\title{
Pattern and Risk Factors of Diabetic Retinopathy among Type 2 Diabetic Patients: Experience in a Tertiary Care Hospital
}

\author{
MD. MOSTARSHID BILLAH,${ }^{1}$ MUHAMMAD ABDUR RAHIM,${ }^{2}$ MD. ANISUR RAHMAN,${ }^{1}$ PALASH MITRA,${ }^{3}$ TUFAYEL \\ AHMED CHOWDHURY, ${ }^{4}$ MD. EMTIAZ HOSSAN, ${ }^{5}$ MD. GOLZAR HOSSAIN ${ }^{6}$, S.M. ASHRAFUZZAMAN, ${ }^{6}$ KHWAJA \\ NAZIM UDDIN, ${ }^{7}$ MD. ABUL MANSUR ${ }^{8}$
}

\begin{abstract}
Background: Diabetic retinopathy is the commonest cause of blindness in the working age group of both developed and developing countries. It is the indicator of all micro-vascular complications of diabetes mellitus. This study was aimed to find out the frequency and pattern of diabetic retinopathy among hospitalized adult type 2 diabetic patients.

Methodology: This cross-sectional study was carried out in the Department of Medicine and Endocrinology of BIRDEM General Hospital, Dhaka over a period of six months. Retinopathy was determined by fundoscopic examination in dilated pupil. Data were collected in preformed questionnaire including demographic characteristics, fundoscopic findings, and laboratory investigation reports with prior informed consent of the patients.

Results: Total patients were 94, male were 52 and female were 42. Mean age of the patients was $52.2 \pm$ II. 12 years. Hypertension was the most common (42.8\%) co-morbid condition followed by dyslipidemia (33\%), nephropathy (34\%), neuropathy (21.3\%), ischemic heart disease (9.6\%) and stroke (5.3\%). Study showed $37.23 \%$ Patient had good glycemic control (HbAlC < $7 \%$ ) and $62.77 \%$ had poor glycemic control. The frequency of retinopathy of any form was present in $36.2 \%$ patients. Among them, non-proliferative diabetic retinopathy (NPDR) was present in $78.79 \%$, proliferative diabetic retinopathy (PDR) $6.06 \%$, maculopathy $6.06 \%$, both maculopathy and PDR in $9.09 \%$ diabetic patients. Among NPDR, $46.15 \%$ was mild, $26.92 \%$ was moderate and $26.92 \%$ was severe NPDR. This study also revealed retinopathy was more with increase in duration of diabetes $(66.6 \%$ vs. $17.3 \% p=0.01)$, in poorly controlled diabetic than good control ( $52.54 \%$ vs. $8.5 \%, p=0.01$ ), those with hypertension ( $55 \%$ vs. $22 \%, p=0.02$ ), and those having diabetic nephropathy $(78.12 \%$ vs. $14.51 \%, p=0.01)$.

Conclusion: This study showed frequency of diabetic retinopathy was $36.2 \%$ and among retinopathy NPDR was predominate. Poor glycemic control, increase duration of diabetes, presence of other microvascular complication i.e. nephropathy found to be significant risk factors for developing retinopathy.
\end{abstract}

Key Words: Diabetic retinopathy, frequency, pattern, risk factors, type 2 diabetes mellitus.

1. Junior consultant, Nephrology \& Dialysis, BIRDEM General Hospital, Dhaka, Bangladesh.

2. Assistant professor, Nephrology \& Dialysis, BIRDEM General Hospital, Dhaka, Bangladesh.

3. Assistant Registrar, Nephrology \& Dialysis, BIRDEM General Hospital, Dhaka, Bangladesh.

4. Registrar, Nephrology \& Dialysis, BIRDEM General Hospital, Dhaka, Bangladesh.

5. Senior Medical Officer, Nephrology \& Dialysis, BIRDEM General Hospital, Dhaka, Bangladesh.

6. Associate Professor, Department of Endocrinology, BIRDEM General Hospital, Dhaka, Bangladesh.

7. Professor, Department of Internal Medicine, BIRDEM General Hospital, Dhaka, Bangladesh.

9. Professor, Nephrology \& Dialysis, BIRDEM General Hospital, Dhaka, Bangladesh.

Corresponding author: Dr. Md. Mostarshid Billah, FCPS (Medicine), Junior consultant, Nephrology \& Dialysis, BIRDEM General Hospital, Dhaka, Bangladesh, Email: drbillah70@ gmail.com.

\section{Introduction:}

Prevalence of diabetes mellitus (DM) is increasing day by day. The global prevalence of DM has been reported to be $6.6 \%$ for the year 2010 and projected to rise to $7.8 \%$ in the year 2030. ${ }^{1}$ Type 2 diabetes mellitus (T2DM) usually has an asymptomatic phase between onset of hyper-glycemia and clinical diagnosis. Microvascular complication like diabetic retinopathy may be pres-ent at the time of clinical diagnosis. ${ }^{2}$ Diabetic retinopathy does not reduce vision in its early stages when treatment is most effective. Preventing blindness from retinopathy relies on early detection of asymptomatic disease by fundoscopy. Retinal photocoagulation is an effective treatment. ${ }^{3}$ Patients with early onset of DM, longer duration of disease, ${ }^{4}$ with poor glycemic control, ${ }^{5}$ having hypertension, ${ }^{6}$ proteinuria, ${ }^{7}$ anemia, smokers, obese, ${ }^{8}$ pregnant patients and those taking oral contraceptive pills are at increased risk of developing retinopathy. So patients should be screened for early detection of retinopathy. In this study, we have tried to find 
out frequency and pattern of diabetic retinopathy and evaluated some risk factors in our setting.

\section{Material and Methods:}

This cross-sectional study was carried out in the Department of Internal Medicine and Endocrinology of BIRDEM General Hospital Dhaka, Bangladesh from April to September 2012 with the aim to find out frequency of diabetic retinopathy and their severity in hospitalized adult type 2 diabetic patients. A total of 94 hospitalized patients with any duration of DM and of either sex were included in the study. Type 1 DM, gestational diabetes mellitus (GDM) and other specific type of DM and patients with cataract were excluded from study. Informed consent was obtained from the patients after full explanation. Patients were interviewed face to face and data written in a preformed questionnaire. Standard ophthalmoscopic examination in dilated pupil was done by experienced ophthalmologist(s) of the institute and recorded in case record forms. All necessary investigation reports were collected from patient's hospital record that was done from standard laboratory of the institute. Data were processed manually and analyzed with the help of statistical package for social sciences (SPSS) Version 20.0. Quantitative data were analyzed by mean and standard deviation and comparison was done between the groups by student " $t$ " test. Qualitative data were analyzed as percentage and comparison carried out between two groups by Chi-square $\left(\chi^{2}\right)$ and Fisher's Exact test. A probability value $(p)$ of $<0.05$ was considered as statistically significant.

\section{Results:}

Total number of patients was 94, male were $52(55.3 \%)$ and female were $42(44.7 \%)$. The mean age was $52.2 \pm 11.1$ (range $30-80)$ years. Forty six (48.9\%) patients had family history of DM. Duration of DM was $<6$ years in $55.3 \%, 6$ 10 years in $25.5 \%$, and $>10$ years in $19.1 \%$ patients. Hypertension was found to be the most common (42.8\%) co-morbid condition and others are shown in Table I. More than three-fourth (83\%) patients had normal body mass index (BMI) and $13.8 \%$ patients were overweight and $3.2 \%$ were obese.

Table-I

Co-morbid conditions of the study population $(n=94)$

\begin{tabular}{lcc}
\hline Co-morbid condition & Frequency & Percentage \\
\hline Hypertension & 40 & 42.6 \\
Dyslipidemia & 31 & 33 \\
Fatty liver & 9 & 9.6 \\
Ischemic Heart Diseases & 9 & 9.6 \\
\hline
\end{tabular}

Among the diabetic complications 36.2\% had retinopathy, $34 \%$ had nephropathy, $21.3 \%$ had neuropathy (Table-II). Diabetic retinopathy was more in male (55.32\% vs. $44.68 \%$ ) which was statistically not significant ( $p$ value 0.934 ). Regarding types of diabetic retinopathy, non-proliferative diabetic retinopathy (NPDR) was most common form (26/ $34,78.8 \%$ ) and other forms are shown in table III. In this study only $35(37.2 \%)$ patient was found to have good glycemic control and rest $(59,62.8 \%)$ had poor glycemic control. Glycemic status is presented in Table IV.

Table-II

Distribution of diabetic patients on diabetic complication $(n=94)$

\begin{tabular}{lcc}
\hline Complication & Frequency & Percentage \\
\hline Retinopathy & 34 & 36.2 \\
Nephropathy & 32 & 34 \\
Neuropathy & 20 & 21.3 \\
Stroke & 5 & 5.4 \\
Diabetic foot & 3 & 3.1 \\
\hline
\end{tabular}

Table-III

Pattern of diabetic retinopathy $(n=34)$

\begin{tabular}{lcc}
\hline Type of retinopathy & Frequency & Percentage \\
\hline NPDR & 26 & $78.8 \%$ \\
Mild & 12 & $46.2 \%$ \\
Moderate & 7 & $26.9 \%$ \\
Severe & 7 & $26.9 \%$ \\
PDR & 2 & $6.1 \%$ \\
Maculopathy & 2 & $6.1 \%$ \\
PDR \& Maculopathy & 3 & $9.1 \%$ \\
\hline
\end{tabular}

$\mathrm{NPDR}=$ Non-proliferative diabetic retinopathyPDR $=$ Proliferative diabetic retinopathy

Table-IV

Blood glucose and $\mathrm{HbA}_{1 \mathrm{C}}$ in diabetic patients $(n=94)$

\begin{tabular}{lcc}
\hline Blood sugar & Mean $\mathrm{HbA}_{1 \mathrm{C}}$ & Range \\
\hline Fasting blood glucose $(\mathrm{mmol} / \mathrm{L})$ & $8.2 \pm 2.6$ & $4.3-22.1$ \\
Postprandial blood glucose & $11.3 \pm 4.0$ & $5.8-30.1$ \\
$\mathrm{HbA}_{1 \mathrm{C}}(\%)$ & $8.1 \pm 2.1$ & $5.6-17.7$ \\
\hline
\end{tabular}

Retinopathy was present more with increased duration of $\mathrm{DM}$, in poor controlled diabetics than that of good controlled diabetics $(52.54 \%$ vs. $8.5 \%, \mathrm{p}=0.001)$, more in hypertensive patient than those without hypertension (55\% vs. $22.22 \%$ ) and those who have diabetic nephropathy (78.12\% vs. $14.51 \%$ ) (Table V). 
Table-V

Risk factors for diabetic retinopathy

\begin{tabular}{|c|c|c|c|c|}
\hline Risk factors & Number (\%) & $\begin{array}{c}\text { Retinopathy } \\
\text { present }\end{array}$ & $\begin{array}{c}\text { Retinopathy } \\
\text { absent }\end{array}$ & P value \\
\hline \multicolumn{5}{|l|}{ Sex } \\
\hline Male & $52(55.32 \%)$ & $19(36.4 \%)$ & $33(63.46)$ & 0.934 \\
\hline Female & $42(44.68 \%)$ & $15(35.71 \%)$ & $27(64.29 \%)$ & \\
\hline \multicolumn{5}{|l|}{$\operatorname{BMI}\left(\mathrm{kg} / \mathrm{m}^{2}\right)$} \\
\hline $18.5-24.9$ & $78(82.98 \%)$ & $24(30.77 \%)$ & $54(69.23 \%)$ & 0.05 \\
\hline $25-29.9$ & $13(13.82 \%)$ & $8(61.54 \%)$ & $5(38.46 \%)$ & \\
\hline$>30$ & $3(3.19 \%)$ & $2(66.67 \%)$ & $1(33.33 \%)$ & \\
\hline \multicolumn{5}{|c|}{ Duration of Diabetes } \\
\hline$<6$ year & $52(55.32 \%)$ & $9(17.31 \%)$ & $43(82.69 \%)$ & \\
\hline 6-10 year & $24(25.53 \%)$ & $13(54.17 \%)$ & $11(45.83 \%)$ & 0.01 \\
\hline$>10$ year & $18(19.15 \%)$ & $12(66.67 \%)$ & $6(33.33 \%)$ & \\
\hline \multicolumn{5}{|c|}{ Glycemic control } \\
\hline Good $<7 \%$ & $35(37.23 \%)$ & $3(8.57)$ & $32(91.43 \%)$ & 0.01 \\
\hline Poor $>7 \%$ & $59(62.77 \%)$ & $31(52.54 \%)$ & $28(47.46 \%)$ & \\
\hline \multicolumn{5}{|l|}{ Hypertension } \\
\hline Present & $40(42.55 \%)$ & $22(55 \%)$ & $18(45.0 \%)$ & 0.02 \\
\hline absent & $54(57.45 \%)$ & $12(22.22 \%)$ & $42(77.78 \%)$ & \\
\hline \multicolumn{5}{|c|}{ Diabetic nephropathy } \\
\hline Yes & $32(34.04 \%)$ & $25(78.12 \%)$ & $7(21.88 \%)$ & 0.02 \\
\hline No & $62(65.96 \%)$ & $9(14.51 \%)$ & $53(85.48 \%)$ & \\
\hline
\end{tabular}

\section{Discussion:}

This study was aimed to evaluate the frequency, pattern and risk factors of diabetic retinopathy in hospitalized type 2 diabetic patients. In this study the mean age was 52.2 years with standard deviation of mean (SD) \pm 11.12 years. This result was correlated with Abdel-Aal et al. (2008), they reported that mean age of diabetic patients was $54.3 \pm 10.9$ years with $54.4 \pm 10.9$ in male and $53.7 \pm 10.6$ in female. ${ }^{11}$

In the current study, female was found predominant which corresponds with study of Chetthakul et al. ${ }^{\mathbf{1 0}}$ Diabetes was uncontrolled as evident by raised HbA1C (mean 8.13\%). Abdel-al et al. found better glycemic control (7.7 \pm $1.6 \%) .{ }^{11}$ This may be due to lack of knowledge of our people about the control of diabetes. The duration of diabetes mellitus was up to 5 years in $55.3 \%$ of patients, 6 to 10 years in $25.5 \%$ of patients and more than 10 years in $19.1 \%$ of patients. This result was different from the study of Naemat that the duration of diabetes mellitus for the last 7-17 years in $78 \%$ of the cases. ${ }^{12}$ Naemat had included both Type 1 and Type 2 in his study. But in this study all patients were
Type 2 diabetes mellitus and delay of diagnosis of DM, irregular taking of medication and early presence of comorbid condition may be the cause of difference.

In this study, the hypertension was found to be most common (42.8\%) co-morbid conditions followed by dyslipidemia $(33 \%)$, ischemic heart disease $(9.6 \%)$ and stroke $(5.3 \%)$ patients and no associated co-morbid conditions was in 5.5\% of patients. In this regard Gordon et al. found 30.3\% of patients with type 2 diabetes had hypertension and $26.6 \%$ had no associated co-morbid conditions because of uncontrolled diabetes, which leads to early appearance of macro and microvascular complication. ${ }^{13}$

In the current study, retinopathy was present in $36.2 \%$ which correlated with the study of Mohamed F El-Bab 1 et al. that $36.1 \%$ of diabetic patients had retinopathy. ${ }^{14}$ But Ossama A W El Haddad et al. found higher rate $(42.4 \%)$ of retinopathy among the diabetic patients. ${ }^{15}$

Regarding retinopathy NPDR was present in $78.79 \%$ patients, PDR was present in $6.06 \%$, maculopathy $6.06 \%$, 
both maculopathy and PDR was present in $9.09 \%$ diabetic patients. Among NPDR 46.15\% has mild NPDR, 26.92\% has moderate NPDR, $26.92 \%$ has severe NPDR which was correlated with the study of Mohamed F El-Bab 1 et al. where 82.1\% has NPDR, $17.6 \%$ has PDR. $37.1 \%$ has mild NPDR, $22 \%$ has moderate NPDR, $22.4 \%$ has severe NPDR. Ossama A W El Haddad et al also found $60.4 \%$ had mild NPDR. ${ }^{16}$

In this study frequency of retinopathy among male and female patients was $55.9 \& 44.1 \%$. There was no statistically significant difference among two groups. Similar results was found by Tien et al. ${ }^{16}$ That study found that gender was not an independent risk factor of diabetic retinopathy after adjusting metabolic and socioeconomic factors. In our study retinopathy was more in poorly controlled diabetic than good control, more in those with hypertension, more with increase in duration of diabetes and those having diabetic nephropathy. This finding was also supported by Muawyah et al. who found diabetic retinopathy was significantly associated with hypertension, long duration of diabetes, poor glycemic status and with presence of diabetic nephropathy. ${ }^{17}$ Considering the finding of the study it might be recommended that that eye should be assessed periodically by fundoscopy for retinopathy in all patients with DM for early detection of retinopathy. Emphasis should be given to strict glycemic control and other risk factors control to prevent or delay development of retinopathy. This study was conducted largest specialized center (BIRDEM) for the concern population. So, the study population might not represent the whole community and sample size was small. A longitudinal study using large sample size and multiple centers should be conducted to find out the magnitude of the retinopathy in diabetes in both hospital and community level.

\section{Conflict of Interest : None}

\section{References:}

1. Wild S, Roglic G, Green A, Sicree R, King H. Global prevalence of diabetes. Diabetes Care 2004; 27:1047-53.

2. Klein R, Klein BE, Moss SE, Davis MD, DeMets DL. The Wisconsin Epi-demiologic Study of Diabetic Retinopathy. III: prevalence and risk of di-abetic retinopathy when age at diagnosis is 30 or more years. Arch Oph-thalmol 1984; 102: 527-32.

3. Frier BM, Fisher M. Diabetes mellitus. In:Boon NA, Hunter JAA, Haslett C. editors. Davidson's Principles \& Practice of Medicine. 20th ed. Edinburgh: Elsevier 2006; p805-47

4. Klein R, Davis MD, Moss SE, Klein BE, DeMets DL. The Wisconsin Epidemiologic Study of Diabetic Retinopathy. A comparison of retinopathy in younger and older onset diabetic persons. Adv Exp Med Biol 1985;189:321-35.

5. Al-Amer RM, Khader Y. Prevalence and Risk Factors of Diabetic Retinopathy among Jordanian Patients with Type 2 Diabetes. Digital Journal of Opthalmology 2008;14(2).

6. Rema M, Srivastava BK. Does hypertension play a role in diabetic retinopathy? J Asso of Phys India 2005;53:803-8.

7. Rema M, Premkumar S, Anita B, Deepa R, Pradeepa R, Mohan V. Prevalence of diabetic retinopathy in urban India: The Chennai Urban Rural Epidemiology Study(CURES) Eye Study, I. Invest Ophthalmol Vis Sci 2005;46:2328-33.

8. Houlden R, Lau DCW. Management of Obesity in Diabetes. Canadian Journal of diabetes 2008;32(1):77-81.

9. Akhtar M, El-Bab MF, Shawky N, Al-Sisi A, Retinopathy and risk factors in diabetic patients from Al-Madinah AlMunawarah in the Kingdom of Saudi Arabia. Clinical Ophthalmology 2012:6 269-76.

10. Chetthakul, Thanya. "Thailand diabetes registry project: prevalence of diabetic retinopathy and associated factors in type 2 diabetes mellitus.” J Med Assoc Thai 2006; 89(suppl 1):S27-36.

1. Abdel-aal NM, Ahmad AT, Froelicher ES, Batieha AMS, Hamza MM, Ailouni KM. Prevalence of Dyslipedimia in Patients with Type-2 Diabetics in Jordan. Saudi Med J 2008;29(10):1423-28.

11. Naemat K. Clinical study of lipid profile in diabetic patients. Middle East J Fam Med,2006;4(5):19-23.

12. Gordon L, Ragoobirsingh D, Morison EY, Choo-Kang E, Mcgrowder D, Martorell E. Lipid profile in type-2 diabetics and hypertensive patients in the Jamaican population. J Lab Physicians 2010;2(1):25-30.

13. El-Bab MF, Shawky N, Al-Sisi A, Akhtar M .Retinopathy and Risk Factors in Diabetic Patients from Al-Madinah AlMunawarah in the Kingdom of Saudi Arabia Clinical Ophthalmology 2012;6:269-76.

14. Ossama A W El Haddad, Mohammed Kamal Saad Prevalence and risk factors for diabetic retinopathy among Omani diabetics. Br J Ophthalmol 1998;82:901-906.

15. Tien YW, Cheung N, Aung T, Lim SC, Tai ES, Tay WT. Prevalence and Risk Factors of Diabetic Retinopathy: The Singapur Malay Eye Study. Arch Opthalmol 2008;115: 1869-75.

16. Al-Bdour MD, Al-Till MI, Abu Samra KM. Risk Factors for Diabetic Retinopathy among Jordanian Diabetics. Middle East African Journal of Ophthalmology. 2008;15(2):77-80. 